Louisiana State University

LSU Digital Commons

Faculty Publications

School of Animal Sciences

$10-12-2012$

\title{
AMP-activated protein kinase stimulates myostatin expression in C2C12 cells
}

\author{
Arun K. Das \\ Washington State University Pullman \\ Qi Yuan Yang \\ Washington State University Pullman \\ Xing Fu \\ Washington State University Pullman \\ Jun Fang Liang \\ Washington State University Pullman \\ Marcio S. Duarte \\ Washington State University Pullman
}

See next page for additional authors

Follow this and additional works at: https://digitalcommons.Isu.edu/animalsciences_pubs

\section{Recommended Citation}

Das, A., Yang, Q., Fu, X., Liang, J., Duarte, M., Zhu, M., Trobridge, G., \& Du, M. (2012). AMP-activated protein kinase stimulates myostatin expression in $\mathrm{C} 2 \mathrm{C} 12$ cells. Biochemical and Biophysical Research Communications, 427 (1), 36-40. https://doi.org/10.1016/j.bbrc.2012.08.138

This Article is brought to you for free and open access by the School of Animal Sciences at LSU Digital Commons. It has been accepted for inclusion in Faculty Publications by an authorized administrator of LSU Digital Commons. For more information, please contact ir@lsu.edu. 


\section{Authors}

Arun K. Das, Qi Yuan Yang, Xing Fu, Jun Fang Liang, Marcio S. Duarte, Mei Jun Zhu, Grant D. Trobridge, and Min Du 


\title{
AMP-activated protein kinase stimulates myostatin expression in $\mathrm{C} 2 \mathrm{C} 12$ cells
}

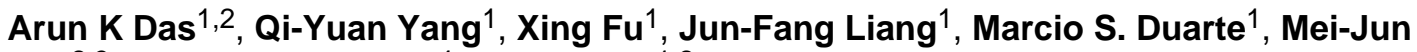 \\ Zhu $^{2,3}$, Grant D. Trobridge ${ }^{4}$, and Min $\mathbf{D u}^{1,2}$ \\ ${ }^{1}$ Department of Animal Sciences, Washington State University, Pullman, WA 99164, USA \\ ${ }^{2}$ Developmental Biology Group, Department of Animal Science, University of Wyoming, Laramie, \\ WY 82071, USA \\ ${ }^{3}$ School of Food Science, Washington State University, Pullman, WA 99164, USA \\ ${ }^{4}$ College of Pharmacy, Washington State University, Pullman, WA 99164, USA
}

\begin{abstract}
AMP-activated protein kinase (AMPK) is a master regulator of energy metabolism in skeletal muscle; AMPK induces muscle protein degradation but the underlying mechanisms are unclear. Myostatin is a powerful negative regulator of skeletal muscle mass and growth in mammalian species. We hypothesized that AMPK stimulates myostatin expression, which provides an explanation for the negative role of AMPK in muscle growth. The objective of this study is to demonstrate that AMPK stimulates myostatin expression using $\mathrm{C} 2 \mathrm{C} 12$ cells as a model. Activation of AMPK by 5-aminoimidazole-4-carboxamide-1- $\beta$-d-riboruranoside (AICAR) dramatically increased the mRNA expression and protein content of myostatin in $\mathrm{C} 2 \mathrm{C} 12$ myotubes, and to a lesser degree in myoblasts. Metformin, another AMPK activator, also stimulated myostatin expression at low concentrations. In addition, ectopic expression of AMPK wild-type a subunit (enhancing AMPK activity) and AMPK K45R mutant (knockdown AMPK activity) enhanced and reduced myostatin expression respectively. These results indicate that AMPK stimulates myostatin expression in $\mathrm{C} 2 \mathrm{C} 12$ cells, providing an explanation for the negative effect of AMPK on muscle growth.
\end{abstract}

\section{Keywords}

AMPK; myostatin; AICAR; metformin; C2C12 cells

\section{Introduction}

AMP-activated protein kinase (AMPK) is a well-characterized sensor of cellular energy status and metabolic stress [1]. Changes in the cellular energy state activate AMPK through several mechanisms involving allosteric regulation of AMPK, activation by upstream AMPK kinase, and diminished activity of phosphatases [2]. AMPK is switched on by an

\footnotetext{
(c) 2012 Elsevier Inc. All rights reserved.

Corresponding author: M. Du, Department of Animal Sciences, Washington State University, Pullman, WA 99164, USA; min.du@wsu.edu; Phone: 509-335-2744.

Publisher's Disclaimer: This is a PDF file of an unedited manuscript that has been accepted for publication. As a service to our customers we are providing this early version of the manuscript. The manuscript will undergo copyediting, typesetting, and review of the resulting proof before it is published in its final citable form. Please note that during the production process errors may be discovered which could affect the content, and all legal disclaimers that apply to the journal pertain.
} 
increase in the AMP/ATP ratio, leading to the phosphorylation of AMPK at Thr 172 by AMPK kinases [3]. Once activated, AMPK promotes glucose and fatty acid uptake and oxidation, while inhibiting lipid synthesis in cells [4] and repressing energy consuming processes e.g. generation of fatty acids [5] and protein synthesis [6].

Regulation of muscle mass depends on a fine balance between muscle protein synthesis and degradation. Activation of AMPK in skeletal muscle down-regulates protein synthesis via inhibition of mammalian target of rapamycin (mTOR) kinase, a key mediator of muscle protein synthesis [7]. It has been reported recently that AMPK activation inhibits cell cycle transition, reducing differentiation of myoblasts into myotubes, and induces muscle protein degradation $[8,9,10,11]$. We previously demonstrated that AMPK enhances muscle protein degradation through promoting the expression of two muscle-specific ubiquitin ligases, muscle atrophy F box (MAFbx) and muscle RING finger 1 (MuRF1) [10]. However, the exact mechanisms linking AMPK to enhanced expression of ubiquitin ligases and enhanced muscle protein degradation remains unclear.

Myostatin is a growth and differentiation factor (GDF 8) belonging to the transforming growth factor (TGF)- $\beta$ superfamily, which acts as a negative regulator of muscle mass [12]. The deletion of myostatin in mice causes a dramatic and widespread increase in skeletal muscle mass, resulted from both hyperplasia and hypertrophy of muscle fibers $[12,13,14]$. Myostatin is capable of inducing muscle atrophy via its inhibition of myoblast proliferation, increasing ubiquitin-proteasomal activity and down-regulating the mTOR protein synthesis pathway [15]. Increases in myostatin mRNA expression induced by both burn injury and dexamethasone injection in rats correlates with the loss of muscle mass $[16,17,18]$. With the above findings, we speculate that AMPK stimulates myostatin expression, providing an important novel mechanism linking AMPK to muscle protein degradation and muscular atrophy. Our data demonstrate that AMPK promotes myostatin expression in $\mathrm{C} 2 \mathrm{C} 12$ myotubes.

\section{Materials and methods}

\section{Chemicals and Antibodies}

5-aminoimidazole-4-carboxamide 1- $\beta$-D-ribonucleoside (AICAR), a specific activator of AMPK [19], and all other chemicals were purchased from Sigma Aldrich (St. Louis, MO). Antibodies against AMPKa, phospho-AMPK at Thr 172, and horseradish peroxidase linked secondary antibody were purchased from Cell Signaling (Danvers, MA). GDF8 (\#sc-6885R) antibody was from Santa Cruze Biotechology, Inc. Anti- $\beta$-tubulin antibody was obtained from Developmental Studies Hybridoma Bank (DSHB, Iowa City, IA).

\section{C2C12 cell culture}

C2C12 myoblasts were obtained from the American Type Culture Collection (ATCC; Manassas. VA) and grown in Dulbecco's modified Eagle medium (DMEM) supplemented with $10 \%$ fetal bovine serum (FBS) and 1\% antibiotics in a humidified atmosphere of $95 \%$ air and $5 \% \mathrm{CO}$ at $37^{\circ} \mathrm{C}$. At $90 \%$ confluence, $\mathrm{C} 2 \mathrm{C} 12$ myoblasts in 6-well plates were incubated with AICR $(0,0.25,0.5$ and $1.0 \mathrm{mM})$. At confluence, myoblasts were induced to fuse into myotubes by using DMEM containing $2 \%$ horse serum (differentiation medium) for $3 \mathrm{~d}$. Then, $\mathrm{C} 2 \mathrm{C} 12$ myotubes in 6-well plates were incubated with AICAR $(0,0.25,0.5$ and $1.0 \mathrm{mM})$ or metformin $(0,0.5,1.5$ and $2.0 \mathrm{mM})$ for $24 \mathrm{~h}$ in the differentiation medium.

\section{Real-time quantitative PCR (RT-PCR)}

Total mRNA was extracted from muscle using TRI reagent (Sigma, St. Louis, MO) and reverse transcribed into cDNA using an iScriptTM cDNA synthesis kit (Bio-Rad, Hercules, 
CA). The primer sets used are shown in Table 1. RT-PCR was performed on a CFX connected TM Real-Time PCR detection system (Bio-Rad) using SYBR Green RT-PCR kit from Bio-RAD. PCR conditions were as follows: $20 \mathrm{~s}$ at $95{ }^{\circ} \mathrm{C}, 20 \mathrm{~s}$ at $56^{\circ} \mathrm{C}$, and $20 \mathrm{~s}$ at 72 ${ }^{\circ} \mathrm{C}$ for 35 cycles. Primer sequence was as following: myostatin forward $\left(5^{\prime}-\right.$

AATCCCGGTGCTGCCGCTAC- $\left.3^{\prime}\right)$ and reverse $\left(5^{\prime}\right.$ GTCGGAGTGCAGCAAGGGCC- $\left.3^{\prime}\right)$; $18 \mathrm{~S}$ rRNA forward $\left(5^{\prime}\right.$ TGCTGTCCCTGTATGCCTCT- $3^{\prime}$ ) and reverse ( $5^{\prime}$-TGTAGCCACGCTCGGTCA-3 ${ }^{\prime}$ ). After amplification, a melting curve $(0.01 \mathrm{C} / \mathrm{s})$ was used to confirm product purity, and the PCR products were electrophoresed to confirm the targeted sizes. Results are expressed relative to $18 \mathrm{~S}$.

\section{Lentivirus transduction of $\mathrm{C} 2 \mathrm{C} 12$ cells}

Plasmids AMPK WT (Plasmid 15991) and AMPK K45R (Plasmid 15992) were obtained from Addgene (Cambridge, MA) [20,21], and sub-cloned into a lentiviral vector (Plasmid $17445)$ using PCR with primers: Forward $\left(5^{\prime}-\right.$ GTGTaCcGGtATTCGCCATGGAGCAGAA-3') and reverse (5' CCGGgtcgacGTTATCAACGGGCTAAAGCAGTGAT-3'). As a result, the amplicons had two new restriction sites, Age1 and Sall. These newly constructed vectors were packaged into vesicular stomatitis virus glycoprotein pseudotyped lentiviral vector virions as previously described [22] and used for transduction. Briefly, C2C12 cells were seeded on 12 plates to reach 90\% confluence and were tranduced with AMPK WT and AMPK K45R lentiviral constructs. Transduction efficiency was monitored by the transduction of a control eGFP lentiviral vector virions. Cells were incubated at $37{ }^{\circ} \mathrm{C}$ in $5 \% \mathrm{CO}_{2}$. After 24 hours, protein was harvested for western blot analysis.

\section{Immunoblotting Analysis}

Western blotting was conducted as previously described [23] using an Odyssey Infrared Imaging System (LI-COR Biosciences, Lincoln, NE). Density of bands was quantified and then normalized according to the tubulin content [20].

\section{Statistical analysis}

Data were analyzed by GLM procedure (SAS Inst., Inc., Cary, NC). Statistical significances were determined by the Tukey's Studentized Range test. P $<0.05$ was considered significant.

\section{Results}

\section{AICAR enhanced myostatin expression in $\mathrm{C} 2 \mathrm{C} 12$ myotubes}

$\mathrm{C} 2 \mathrm{C} 12$ myotubes were treated with various doses of AICAR for $24 \mathrm{~h}$. AICAR treatment induced dose-dependent phosphorylation of AMPK (Fig. 1A), showing the activation of AMPK in response to AICAR. Consistently, the myostatin protein content was increased in a dose dependent manner (Fig. 1B). Such increase in myostatin protein content was at least partially due to elevated mRNA expression (Fig. 1C). Interestingly, the expression of myostatin mRNA in response to AICAR treatment was much more robust in myotubes that myoblasts (Fig. 1D).

To further test the effect of AMPK on myostatin expression, we used another chemical, metformin, which activates AMPK through a different mechanism. We used different concentration of metformin $(0,0.5 \mathrm{mM}, 1.5 \mathrm{mM}$ and $2 \mathrm{mM})$ to treat $\mathrm{C} 2 \mathrm{C} 12$ myotubes for 24 h. Metformin at low concentration $(0.5 \mathrm{mM})$ increased the mRNA expression of myostatin but reduced myostatin expression when higher concentrations were used (Fig. 2A). 
Consistently, $0.5 \mathrm{mM}$ metformin increased myostatin protein concentration (Fig. 2B) while

higher metformin concentrations decreased myotatin protein levels.

\section{AMPK KO reduced myostatin protein in $\mathrm{C} 2 \mathrm{C} 12$ cells}

Because chemicals might have nonspecific effects, we further used ectopic expression to test the role of AMPK in myostatin expression in $\mathrm{C} 2 \mathrm{C} 12$ cells. We transducted $\mathrm{C} 2 \mathrm{C} 12$ cells with lentiviruses carrying a construct expressing AMPK wild-type (AMPK WT) or AMPK mutant (AMPK K45R) respectively. After $36 \mathrm{~h}$ following vector exposure, the myostatin protein level in AMPK knockdown cells (AMPK K45R) was much lower compared to control and AMPK WT (Fig. 3A). These data clearly show that AMPK activation increased mRNA and protein levels of myostatin in $\mathrm{C} 2 \mathrm{C} 12$ cells (Fig. 3B).

\section{Discussion}

In skeletal muscle, protein levels are determined by relative rates of protein synthesis and breakdown. The balance between synthesis and degradation of intracellular components determines the overall muscle fiber size. AMPK was recently shown to increase myofibrillar protein degradation through enhancing the expression of MAFbx and MuRF1 [11], but the exact mechanisms linking AMPK to ubiquitin ligase expression and muscle atrophy is unclear. A recent study showed that myostatin is correlated with the expression of MAFbx [24]; because myostatin is a well known inhibitor of muscle growth, we hypothesized that AMPK promotes muscle protein degradation and inhibits muscle growth partially through enhancing myostatin expression. Indeed, we found that AMPK promotes myostatin expression in $\mathrm{C} 2 \mathrm{C} 12$ cells.

While AICAR dose dependently increased myostatin expression, the effect of metformin on myostatin expression appears to be more complicated. Low concentration of metformin increased myostatin expression but higher concentration down-regulated myostatin expression and protein level. The possible explanation is that at high levels, metformin overactivates AMPK, which inhibits overall protein synthesis and anabolic metabolism including myostatin expression. The reduced expression of MSTN may act to protect cells from inhibition by AMPK during myogenesis [25]. To further confirm that AMPK activation plays a key role in myostatin protein level in $\mathrm{C} 2 \mathrm{C} 12$ cells, we transducted $\mathrm{C} 2 \mathrm{C} 12$ cells with lentiviruses carrying AMPK wild-type to increase or AMPK K45R mutant to knock down AMPK activity. Here, we use a lentiviral vector system due to the high transduction efficiency in $\mathrm{C} 2 \mathrm{C} 12$ cells. Lentiviruses efficiently integrate resulting in stable expression, whereas plasmid transfection leads to mostly transient expression with rare cells integrating plasmid DNA leading to stable expression. Consistent with data from chemical activation of AMPK, knocking down AMPK through ectopic expression reduced both myostatin mRNA expression and protein content in myoblasts. In summary, our results show that AMPK activation by AICAR, metformin and ectopic expression induced myostatin mRNA expression and increased its protein level in $\mathrm{C} 2 \mathrm{C} 12$ cells.

It is interesting to note, though, the effect of AMPK on myostatin expression appears to be specific to myotubes, not myoblasts. The exact mechanism for such differential effects is unclear, but may be related to the isoform specific roles of AMPK. AMPK a 2 subunit is highly expressed in myofibers, and is the major subunit regulating energy metabolism [26,27]. The high abundance of AMPK a 2 subunit in myotubes may render it more responsive to environment factors and correlated with the muscle protein homeostasis via myostatin.

To corroborate our finding, recently studies also show that myostatin plays a role in energy metabolism. Myostatin regulates glucose metabolism in $\mathrm{C} 2 \mathrm{C} 12$ myotubes in vitro and in 
vivo, an effect likely mediated by activating AMPK $[28,29]$. For the first time, we observed that AMPK induces myostatin expression, establishing the feed-forward loop between AMPK and myostatin to restrict muscle growth. This is an important addition to the current knowledge. Previously, AMPK has been demonstrated to induce cell autophagy [30] and inhibition of mTOR signaling and overall protein synthesis [31]. Our observation hereby provides an additional mechanism for the regulatory role of AMPK in muscle growth. It is novel and important because it establishes the link between AMPK and myostatin, critical pathways regulating energy metabolisms and muscle sizes respectively.

\section{Acknowledgments}

The work was supported by NIH R01HD067449.

\section{References}

1. Hardie DG. New roles for the LKB1 $\rightarrow$ AMPK pathway. Current opinion in cell biology. 2005; 17:167-173. [PubMed: 15780593]

2. Hardie DG, Carling D, Carlson M. The AMP-activated/SNF1 protein kinase subfamily: metabolic sensors of the eukaryotic cell? Annual review of biochemistry. 1998; 67:821-855.

3. Hardie DG. Minireview: the AMP-activated protein kinase cascade: the key sensor of cellular energy status. Endocrinology. 2003; 144:5179-5183. [PubMed: 12960015]

4. Hardie DG, Hawley SA. AMP - activated protein kinase: the energy charge hypothesis revisited. BioEssays. 2001; 23:1112-1119. [PubMed: 11746230]

5. Henin N, Vincent MF, Gruber H, Van den Berghe G. Inhibition of fatty acid and cholesterol synthesis by stimulation of AMP-activated protein kinase. The FASEB Journal. 1995; 9:541-546.

6. Bolster DR, Crozier SJ, Kimball SR, Jefferson LS. AMP-activated protein kinase suppresses protein synthesis in rat skeletal muscle through down-regulated mammalian target of rapamycin (mTOR) signaling. Journal of Biological Chemistry. 2002; 277:23977-23980. [PubMed: 11997383]

7. Mounier R, Lantier L, Leclerc J, Sotiropoulos A, Foretz M, Viollet B. Antagonistic control of muscle cell size by AMPK and mTORC1. Cell cycle (Georgetown, Tex). 2011; 10:2640.

8. Williamson DL, Butler DC, Alway SE. AMPK inhibits myoblast differentiation through a PGC-1alpha-dependent mechanism. American Journal of Physiology Endocrinology Metabolism. 2009; 297:E304-E314.

9. Fulco M, Cen Y, Zhao P, Hoffman EP, McBurney MW, Sauve AA, Sartorelli V. Glucose restriction inhibits skeletal myoblast differentiation by activating SIRT1 through AMPK-mediated regulation of Nampt. Developmental and Cell. 2008; 14:661-673.

10. Tong JF, Yan X, Zhu MJ, Du M. AMP-activated protein kinase enhances the expression of muscle-specific ubiquitin ligases despite its activation of IGF-1/Akt signaling in C2C12 myotubes. J Cell Biochem. 2009; 108:458-468. [PubMed: 19639604]

11. Sanchez AMJ, Csibi A, Raibon A, Cornille K, Gay S, Bernardi H, Candau R. AMPK promotes skeletal muscle autophagy through activation of forkhead FoxO3a and interaction with Ulk1. Journal of cellular biochemistry. 2012; 113:695-710. [PubMed: 22006269]

12. McPherron AC, Lee SJ. Double muscling in cattle due to mutations in the myostatin gene. Proceedings of the National Academy of Sciences. 1997; 94:12457.

13. McPherron AC, Lawler AM, Lee SJ. Regulation of skeletal muscle mass in mice by a new TGFbeta superfamily member. Nature. 1997; 387:89-89.

14. Kambadur R, Sharma M, Smith TPL, Bass JJ. Mutations in myostatin (GDF8) in double-muscled Belgian Blue and Piedmontese cattle. Genome research. 1997; 7:910-915. [PubMed: 9314496]

15. Elliott B, Renshaw D, Getting S, Mackenzie R. The Central Role of Myostatin in Skeletal Muscle and Whole Body Homeostasis. Acta Physiologica. 2012

16. Lang CH, Silvis C, Nystrom G, Frost RA. Regulation of myostatin by glucocorticoids after thermal injury. The FASEB Journal. 2001; 15:1807-1809. 
17. Salehian B, Mahabadi V, Bilas J, Taylor WE, Ma K. The effect of glutamine on prevention of glucocorticoid-induced skeletal muscle atrophy is associated with myostatin suppression. Metabolism. 2006; 55:1239-1247. [PubMed: 16919545]

18. Artaza JN, Bhasin S, Mallidis C, Taylor W, Ma K, Gonzalez-Cadavid NF. Endogenous expression and localization of myostatin and its relation to myosin heavy chain distribution in $\mathrm{C} 2 \mathrm{C} 12$ skeletal muscle cells. Journal of cellular physiology. 2002; 190:170-179. [PubMed: 11807821]

19. Corton JM, Gillespie JG, Hawley SA, Hardie DG. 5-aminoimidazole-4-carboxamide ribonucleoside. A secific method for activating AMP-activated protein kinase in intact cells? European Journal of Biochemistry. 1995; 229:558-565. [PubMed: 7744080]

20. Zhao JX, Yue WF, Zhu MJ, Du M. AMP-activated protein kinase regulates beta-catenin transcription via histone deacetylase 5. J Biol Chem. 2011; 286:16426-16434. [PubMed: 21454484]

21. Zhao J, Yue W, Zhu MJ, Sreejayan N, Du M. AMP-activated protein kinase (AMPK) cross-talks with canonical Wnt signaling via phosphorylation of beta-catenin at Ser 552. Biochem Biophys Res Commun. 2010; 395:146-151. [PubMed: 20361929]

22. Munoz NM, Beard BC, Ryu BY, Luche RM, Trobridge GD, Rawlings DJ, Scharenberg AM, Kiem HP. Novel reporter systems for facile evaluation of I-SceI-mediated genome editing. Nucleic Acids Res. 2012; 40:e14. [PubMed: 22110042]

23. Zhao JX, Yue WF, Zhu MJ, Du M. AMP-activated Protein Kinase Regulates $\beta$-Catenin Transcription via Histone Deacetylase 5. Journal of Biological Chemistry. 2011; 286:1642616434. [PubMed: 21454484]

24. Cong H, Sun L, Liu C, Tien P. Inhibition of atrogin-1/MAFbx expression by adenovirus-delivered small hairpin RNAs attenuates muscle atrophy in fasting mice. Hum Gene Ther. 2011; 22:313324. [PubMed: 21126200]

25. Miyake M, Takahashi H, Kitagawa E, Watanabe H, Sakurada T, Aso H, Yamaguchi T. AMPK activation by AICAR inhibits myogenic differentiation and myostatin expression in Cattle. Cell and Tissue Research. 2012 (in press).

26. Putman CT, Martins KJ, Gallo ME, Lopaschuk GD, Pearcey JA, MacLean IM, Saranchuk RJ, Pette D. Alpha-catalytic subunits of 5'AMP-activated protein kinase display fiber-specific expression and are upregulated by chronic low-frequency stimulation in rat muscle. Am J Physiol Regul Integr Comp Physiol. 2007; 293:R1325-1334. [PubMed: 17553841]

27. Imai K, Inukai K, Ikegami Y, Awata T, Katayama S. LKB1, an upstream AMPK kinase, regulates glucose and lipid metabolism in cultured liver and muscle cells. Biochem Biophys Res Commun. 2006; 351:595-601. [PubMed: 17083919]

28. Chen Y, Ye J, Cao L, Zhang Y, Xia W, Zhu D. Myostatin regulates glucose metabolism via the AMP-activated protein kinase pathway in skeletal muscle cells. The International Journal of Biochemistry \& Cell Biology. 2010; 42:2072-2081.

29. Zhang C, McFarlane C, Lokireddy S, Bonala S, Ge X, Masuda S, Gluckman PD, Sharma M, Kambadur R. Myostatindeficient mice exhibit reduced insulin resistance through activating the AMP-activated protein kinase signalling pathway. Diabetologia. 2011; 54:1491-1501. [PubMed: 21347623]

30. Kim J, Kundu M, Viollet B, Guan KL. AMPK and mTOR regulate autophagy through direct phosphorylation of Ulk1. Nat Cell Biol. 2011; 13:132-141. [PubMed: 21258367]

31. Inoki K, Zhu T, Guan KL. TSC2 mediates cellular energy response to control cell growth and survival. Cell. 2003; 115:577-590. [PubMed: 14651849] 


\section{Highlights}

1. For the first time, we reported that AMPK enhances myostatin expression.

2. Metformin, a common anti-diabetic drug, enhances myostatin expression.

3. Knockout AMPK reduces myostatin expression in muscle cells.

4. AMPK regulates muscle growth at least partially through enhancing myostatin expression. 
A

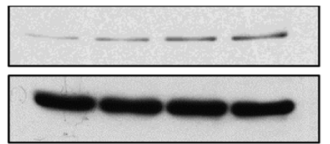

P-AMPK

$\beta$-Tubulin

$\begin{array}{llll}0 & 0.25 & 0.5 & 1.0\end{array}$

AICAR (mM)

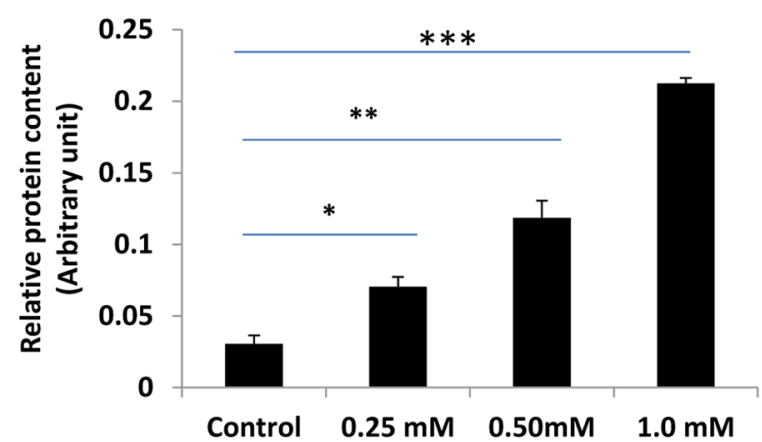

C

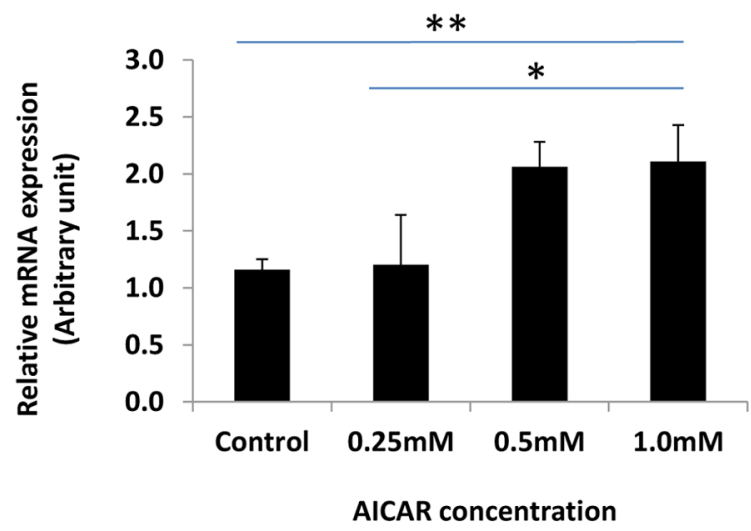

B

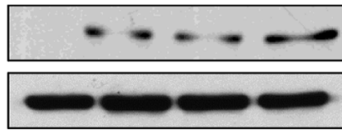

Myostatin

$\beta$-Tubulin

$\begin{array}{lllll}0 & 0.25 & 0.5 & 1.0 & \text { AICAR (mM) }\end{array}$

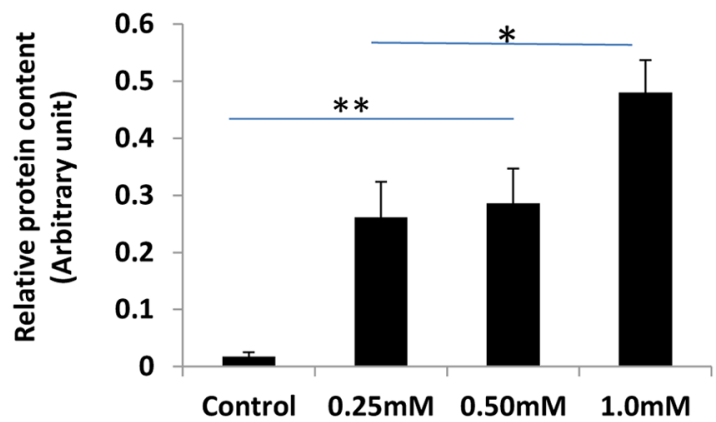

D

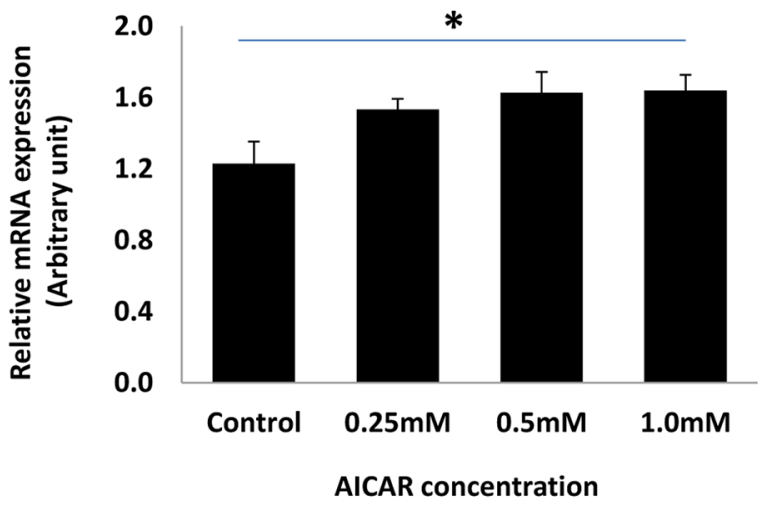

Fig. 1.

AMP-activated protein kinase (AMPK) activation stimulated by AICAR induced myostatin mRNA expression in C2C12 myotubes and myoblasts. A) p-AMPK level in myotubes; B) Myostatin protein concentration inn myotubes; C) Myostatin mRNA expression in myotubes; D) Myostatin mRNA expression in C2C12 myoblasts. C2C12 myoblasts or myotubes were treated with different concentration of $\operatorname{AICAR}(0,0.25,0.5$ and $1.0 \mathrm{mM})$. $(* * P<0.01 ; * P<0.05$, Mean $\pm \mathrm{SE} ; \mathrm{n}=3)$ 
A
B
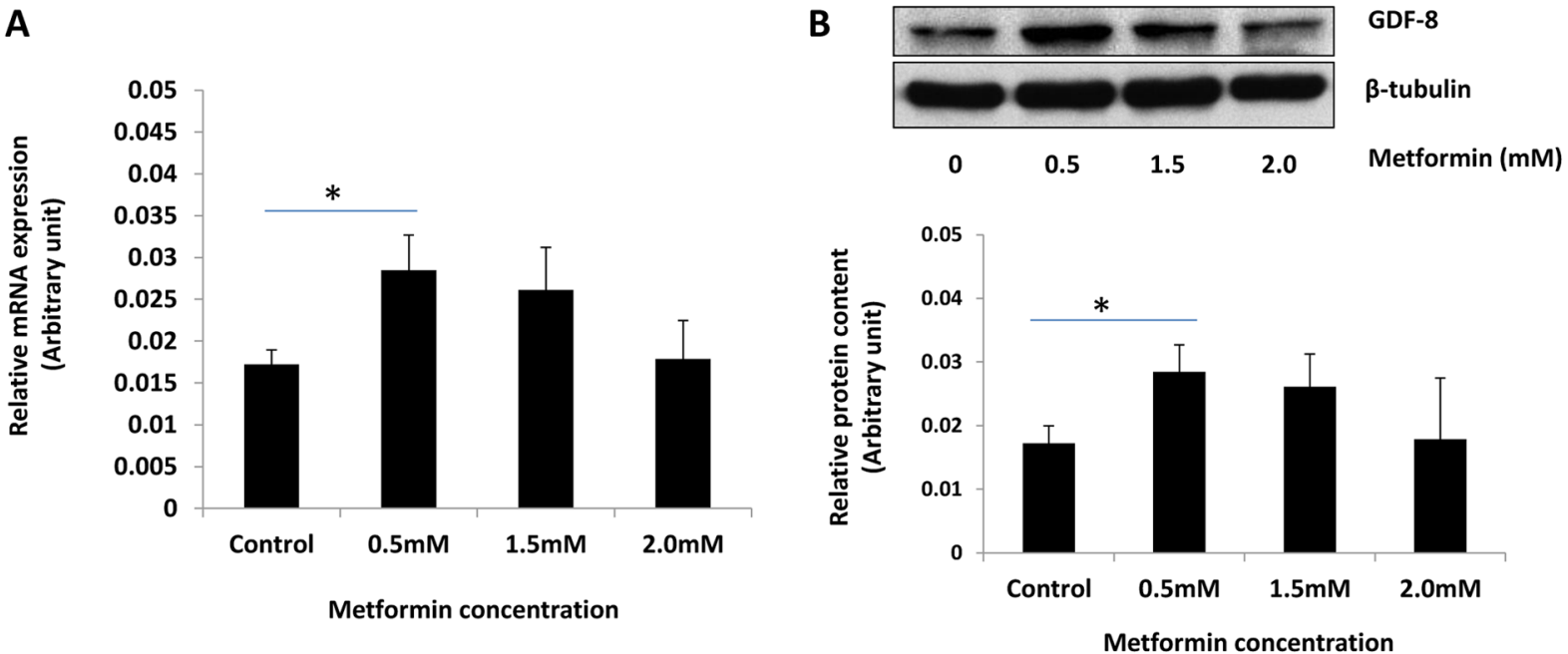

Fig. 2.

Metformin enhanced myostatin mRNA expression and protein concentration in $\mathrm{C} 2 \mathrm{C} 12$ myotubes. A) Myostatin mRNA expression; B) Myostatin protein concentration. C2C12 myoblasts were treated with different concentration of metformin $(0,0.5,1.5$ and $2.0 \mathrm{mM})$ after inducing myotube formation for $24 \mathrm{~h} .(* P<0.05$, Mean $\pm \mathrm{SE} ; \mathrm{n}=3$ ) 
A

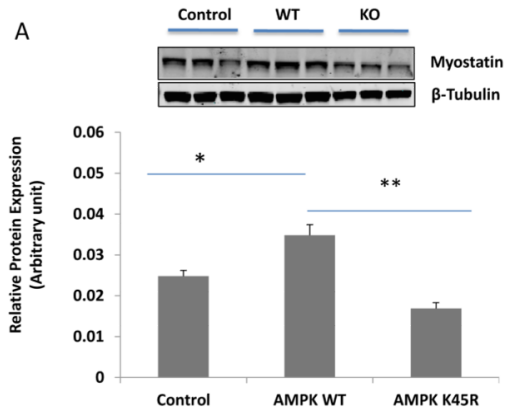

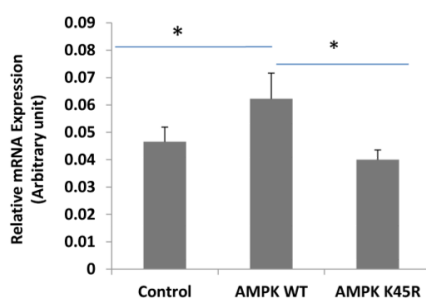

Fig. 3.

Myostatin protein concentration and mRNA expression in $\mathrm{C} 2 \mathrm{C} 12$ cells ectopically expressing AMPK wild-type (WT) or K45R mutant a-subunit. C2C12 cells were transduced with either AMPK-WT or AMPK-K45R lentiviral constructs. A) Total myostatin protein concentration; B) Myostatin mRNA expression. (** $P<0.01 ; * P<0.05$, Mean $\pm \mathrm{SE}$; $\mathrm{n}=3$ ) 